\title{
Н.Ю. Яськова
}

ФГБОУ ВПО «МГСУ»

\section{ЦИКЛИЧЕСКОЕ «ДЕЖАВЮ» ПАРАДИГМ РАЗВИТИЯ СФЕРЫ НЕДВИЖИМОСТИ}

\begin{abstract}
Исследована проблема циклического развития научных школ и их инновационных идей в сфере пространственно-территориального девелопмента недвижимости. Фазы цикла исследованы на примере архитектурного направления «Баухауз». Это позволило выявить требования и особенности развития новых технологических платформ, а также создать эфффективные фрорматы государственно-частного партнерства. Цикличность развития деловой активности в условиях осознания эволюции смыслов использования междисциплинарных подходов позволила сформировать адекватную парадигму развития.

Ключевые слова: архитектурное направление, ремесло, инновационная платсрорма, пространственная реструктуризация, государственный девелопмент, стратегия развития, городская среда, устойчивое развитие, организационно-экономическая надежность, планирование.
\end{abstract}

Поистине удивительны практические проекции теории циклов. Особенно, если речь идет не о «голубой» науке, а о нашей повседневной жизни. Еще не успев осмыслить межциклические взаимодействия и взаимовлияния в решении, к примеру, жилищного вопроса, жизнь снова и снова заставляет возвращаться к точкам циклического роста и развития сферы недвижимости. Наши пристрастия от многоквартирных вариантов и вертикальных городов вновь устремляются к малоэтажкам. Циклы задают вектор развития и наукам о природе, и наукам о человеке, и наукам об обществе. Последние, не успев стереть наскучившие социальные шаблоны, вновь и вновь актуализируют «моду из комода», развивая то принципы планирования, то нормативную базу ценообразования, то адресное, переиначенное на современный сленг, - ручное управление.

Многие попытки задать обществу некие стереотипы, если и не предупреждали неизбежные кризисы развития, то как минимум смягчали его социальные последствия. Они, будучи нацелены на смягчение проблемы, а не на искоренение причин ее возникновения, демонстрируют свою низкую эффективность. Так, сфера недвижимости традиционно смягчала диспропорции и противоречия развития. Ее реструктуризация исторически становилась «палочкой-выручалочкой» для вывода национальных экономик из стагнации и кризисов. Между тем базовые противоречия оставались, но проявляли себя не в антагонистической форме.

Время подтвердило убежденность классиков марксизма-ленинизма в том, что, несмотря на периоды высокоэффективного развития, обеспечение устойчивого развития социально неоднородного общества потребления бесперспективно. Становясь заложниками расширения и приумножения потребностей, их материальная составляющая из мотива развития превращается в его самый опасный тормоз. Это особенно очевидно в сфере недвижимости. По своей эко- 
номической сути капитал в форме недвижимости способен превращать все пространство жизнедеятельности в гармоничную животворящую среду и соответственно в ресурс развития. Но если оценить опасный уровень «омертвления» капитала, то объемы замороженной недвижимости, непродуктивно используемой земли, квартир на будущее, заброшенных сельхозстроений и прочего поистине ужасающи. Оценка колеблется от 15 до 40 \% от потенциального объема недвижимости, который может обеспечивать процесс развития. Это, по мнению экспертов [1], является вполне очевидным следствием продолжающегося разрыва уровня доходов самой состоятельной и малообеспеченной групп граждан. Одни непродуктивно используют тысячи квадратных метров, либо сберегают накопления в форме недвижимости, другим не по силам удовлетворить минимальные потребности в жилье, что, несомненно, снижает продуктивность их труда.

Накопление богатства, с одной стороны, необходимое условие реализации масштабных замыслов, с другой, мощнейший тормоз при отсутствии мотивации у собственника. Практика показала, что в условиях «омертвления» или низкопродуктивного использования капитала владельцев недвижимости можно административно «прессовать», можно периодически заинтересовывать, тратя при этом ресурсы или недополучая результаты. В крайних случаях, в периоды революционных преобразований, собственность может быть экспроприирована. Таким образом, устойчивое развитие невозможно, ибо отсутствует согласование экономических интересов. Скоординированные в режиме принуждения действия решают, как правило, локальные задачи в пределах определенного периода времени. А без внутренней целевой мотивации партнерские связи все равно «рассыпаются», непрерывно требуя адресного регулирования. В этой связи за рубежом появилась даже специальная наука инфорсмента системы мер и условий, направленных на принуждение каждой стороны экономических отношений, фиксируемых в заключенных договорах, выполнить свои обязательства. «Не хочешь - заставим» как метод синхронизации деятельности разнотипных субъектов хозяйственной среды на различных фазах циклов развития, особенно в мобилизационные периоды развития советского периода, многократно подтвердил свою приемлемость, но не эффективность решения отдельных задач. Торможение темпов развития, четко улавливаемое государственными статистическими органами, становилось не единственной опасностью. Цена выполнения планов возрастала, страдало качество развития, подрывая его основы. Затоваривание и дефицит, существенное падение эффективности хозяйствования, дисбалансы и ужасающе неэффективные управленческие решения в угоду политическим дивидендам явились очевидным следствием осуществления стратегии инфорсмента.

Жизнь показала - устойчивые форматы развития возникают естественным путем, а циклы деловой активности, формируемые деловой и творческой средой, зачастую развиваются вопреки политическим амбициям и воле власти. Справедливости ради отметим, что власть, несомненно, способна не только ускорять развитие, но и создать невыносимые условия деятельности и даже разваливать бизнес, заставляя его перемещаться в другие сферы деятельности или даже в другие страны. Разумеется, востребованы другие, прямо противо- 
положные, сценарии. Циклические всплески развития, рожденные синхронизацией усилий власти, хозяйственной и научной сред, будучи осознанно поддержанными участниками, способны рождать устойчивые тренды развития [2]. К примеру, в области решения проблемы экспортных поставок энергоресурсов за счет строительства нового типа производственной недвижимости - трубопроводов, совместными усилиями была создана газо- и нефтетранспортная система, которая по сей день является стратегическим преимуществом страны.

В настоящее время, когда только ленивый не говорит о необходимости пространственной реструктуризации с целью возврата к истинным иеенностям бытия [3] - близости к природе, «живому» жилью, стабильности семейных отношений, нарастающему неприятию роскоши и в целом возникающей тяге к простоте, удобству и функциональности не только в окружающем, но и во внутреннем мире, все очевиднее становится возврат к социально-либеральным идеям. Стремление к компактным формам деятельности, гибким графикам занятости, ясным правилам взаимодействия с обществом и природой, партнерами и конкурентами, прозрачности намерений и открытости результатов деятельности, ответственности за бизнес и социальные обязательства перед обществом становятся все более очевидным содержанием циклов роста, объединяющих развитые и развиваюшиеся страны.

В смысле сближения общечеловеческих ценностей и конструктивных идей развития государственные границы действительно перестают быть препятствием. Тому множество примеров. Так, архитектурная школа Баухауз, созданная в 1919 г. в немецком городе Веймаре, задала более чем на столетие стилистику сферы недвижимости не только в различных странах, но и на разных континентах. Баухауз изначально готовил художников для работы в промышленности, затем школа развилась, используя комплексный подход, объединивший искусство, ремесло и научно-технический прогресс. Новые принципы обустройства жизнедеятельности придавали ей новые смыслы. Школа Баухауз оказала огромное влияние на архитекторов и дизайнеров всего мира, впрочем, не потеряв своей актуальности до сих пор. Более того, пережив стагнацию и даже идейный кризис, она не перестает удивлять своими художественными и функциональными идеями, завоевывая потребительские симпатии вне государственных границ, национальных традиций, религиозных предпочтений и даже уровня доходов [4, 5].

Являя собой классический пример цүиклически восходящзей траектории развития, концепция Баухауз требует серьезного исследования. В ее основе было изначально заложено желание креативного архитектора Вальтера Гропиуса перестроить общество, создав гармоничную предметную среду и изменив формы и начинку недвижимости $[6,7]$. Автору идеи не были чужды социалистические ценности. Их проекция на структуризацию пространства жизнедеятельности выразилась в «Манифесте Баухауза», в котором Гропиус призвал:

1. Разрушить барьер между художником и ремесленником.

2. Забыть о классовых различиях и формировать предметную среду для Bcex.

3. Создать здание будущего, в котором архитектура, скульптура и живопись сольются воедино. 
Образно выражаясь, свое новое здание Гропиус называл «хрустальным символом новой веры». Именно новый образ синтезированного из множества предметных областей смысла привлек уникальных деятелей культуры, архитектуры и искусства (Г. Майера, М. Роэ, М. Брейера, В. Кандинского, П. Клее, Й. Иттена и др.). Подмастерья, так называли студентов, учились не просто рисунку, а основам дизайна и теории цвета. Большое внимание уделяли контрастам, свойствам и сочетаниям материалов, психологии восприятия цвета, пониманию абстракции и др. Заканчивая базовый курс, подмастерья выбирали одну из ремесленных мастерских по стеклу, керамике, тканям, металлу, не только экспериментируя с формами и свойствами различных материалов, но и доводя их до промышленного образца.

Постепенно формы предметного мира Баухауза упрощались, подстраиваясь под требования массового производства. Светильники и стулья, столы и панно, функциональные предметы домашнего обихода и по сей день массово распространены, став нормой потребления и основой таких брендов, как «Икеа». Благодаря серийному производству, произведения искусства все больше входили в обиход промышленных и офисных зон, а также становились неотъемлемой частью жилой сферы $[8,9]$.

Уже в 1925 г. Баухауз стал способен дополнять грантовую поддержку массовым производством и продажей работ студентов. Индустриальный функиионализм недвижимости, сращивая искусство и производство, сделал доступным современный формат пространства жизнедеятельности для всех.

Оценивая востребованность и актуальность идей и смыслов школы Баухауз, нельзя не отметить их ориентированность на освоение не только профессиональных, но и общекультурных компетенций. В основе обучения лежали, помимо специальных предметов и прикладных технологий, лекции по экономике, марксизму и психологии [10]. Ханнес Мейер, сменивший в 1928 г. Гропиуса, развивал идеи Баухауза в следующих направлениях:

форма должна быть не только эстетичной, но и подчиняться назначению;

форматирование недвижимости должно быть эффективным, ибо во всех случаях необходимо учитывать себестоимость;

приоритет массового спроса и в частности потребностей рабочего класса.

Впоследствии школа была деполитизирована, но промышленные зоны и рабочие городки по-прежнему остались их визитной карточкой [11] . К слову, X. Мейер и еще 30 архитекторов еще до Второй мировой войны переехали в СССР. Их соцгородки и частично реализованные генпланы до сих пор можно увидеть в городах Магнитогорске, Перми, Орске и др.

Эксперименты Баухауза, комплексно охватившие архитектуру, живопись, дизайн, давали также путевку в жизнь новым материалам и строительным технологиям. Разработанные предметы обихода и дизайнерские находки в настоящее время насчитывают более 26 тыс. работ, большая часть которых реализована в промышленных проектах и серийно выпускается по сей день [12].

Что же позволило школе Баухауз оставить столь существенный след в искусстве, архитектуре, материаловедении и в целом в сфере недвижимости? За счет чего удавалось сжимать фазы кризисов и застоев и подкреплять динамику роста? Почему творческий потенциал Баухауза продолжал развиваться в ус- 
ловиях новой среды, к примеру, в США и СССР? Ведь творческие традиции старой Европы существенно отличались от формирующихся американских или советских. Раскручивая восходящую спираль развития Баухауза и останавливаясь на реперных точках перелома тенденций, нельзя не отметить их междисциилинарный, практико- и потребительски ориентированный, ресурсоэкономный характер.

Изучая ретроспективу, невозможно не заметить очевидных аналогий с научно-практической школой пространственно-территориального девелопмен$m a$, формирующейся ныне учеными двух научно-образовательных центров: МГСУ и РАНХиГС при Президенте РФ. Посягнув на научное обоснование реструктуризации пространства жизнедеятельности, в ее основу была положена идея гармоничного, а значит устойчивого развития человека, общества и природы [13]. Напитываясь смыслами различных сфер деятельности, отстройка и реконструкция сегментов рынка недвижимости осуществляется инвестиционно-строительным бизнесом [14]. Он перестает быть безыдейным механизмом, функционирующим по принципу «что прикажете» или «потребитель/заказчик всегда прав» и др. Инвестиционно-строительный бизнес становится избирательным как в отношении использования земельных ресурсов и природных дивидендов, развивая различные подходы к лэнд-девелопменту, так и в отношении подготовки кадров, управляющих недвижимостью. Собственники инвестиционно-строительного бизнеса давно убедились, что стройка требует высокого профессионализма и лишь в немногих сегментах позволителен низкоквалифицированный труд. Для вывода сферы недвижимости на новую восходящую волну роста и развития нужны настоящие мастера своего дела, совместными усилиями способные не только высокоэффективно использовать ресурсы, но и рождать новые смыслы формируемой структуры недвижимости [15].

Предлагаемая парадигма новой экономической школы реструктуризации пространства жизнедеятельности (РПЖ) должна позволить на практике.

1. Думать глобально, действовать локально! (Девиз Римского клуба)

2. Не навредить ни природе, ни обществу, ни человеку! (Клятва Гиппократа, Принцип Гринпис)

3. Строить пространство для всех: бедных и богатых, образованных и безграмотных, молодых и пожилых! (Принцип школы Баухауз)

4. Бизнес должен быть социально ответственным! (Декларация современной теории управления)

5. Рисковать только собственными ресурсами! (Кодекс предпринимателя)

К базовому, сформированному в различных предметных областях перечню, школа РПЖ добавляет собственные принципы:

6. Капитализировать ресурс и результат, проект и бизнес!

7. Сотрудничать, а не конкурировать!

8. Считать и оборачивать! Сказать нет бессмысленным накоплениям!

9. Опережать время! Изучать перспективные потребности!

10. Ориентироваться на сильнейшего! Учиться всегда и у всех! Делиться опытом!

11. Быть готовым извлечь пользу из неудач и превратить проблему в возможность! 
Выявленные принципы и аксиомы новой школы пространственной реструктуризации носят не просто частично заимствованный из разных областей экономической науки, но и развивающийся характер. Взятые в совокупности они не столько принципиально изменяют цикл развития недвижимости, сколько наполняют его уточненными смыслами, в т.ч. развивая постулаты школы Баухауз и используя лучшие методы из практики социалистического хозяйства. И те, и другие будили деловую активность, обеспечивая объединительный тренд развития. История Баухауза, социалистического хозяйства, а впоследствии экологических школ, теории устойчивого развития и др. удерживали восходящий характер цикла не менее столетия, придавая устойчивость развитию и объединяя его участников. В настоящий момент без объединительной идеи и противостояния «омертвлению» капитала деградация капитальных фондов неизбежна. Именно поэтому так необходимо и востребовано циклическое «дежавю».

\section{Библиографический список}

1. Яськова Н.Ю., Сергеев И.М., Полинов А.А. Незавершенное строительство и виртуальный экономический рост // Экономика строительства. 2004. № 8. С. 2-13.

2. Яськова Н.Ю. Тенденции развития строительных корпораций в новых условиях // Научное обозрение. 2013. № 6. С. 174-178.

3. Яськова Н.Ю. Развитие концептуальных положений управления процессами инвестиционно-строительной деятельности // Вестник Иркутского государственного технического университета. 2012. № 11 (70). С. 278-280.

4. Дросте М. Баухауз (1919-1933). Реформа и авангард / пер. с фр. Ю.Ю. Котовой. М. : Арт-Родник, 2008. 96 с.

5. Харшак M. «Баухаус» — место, где родился дизайн // Advertology.Ru. Режим доступа: http://www.advertology.ru/article13833.html. Дата обращения: 15.12.2014.

6. Гропиус В. Границы архитектуры / пер. с англ. А.С. Пинскер, В.Р. Аронова, В.Г. Калиша. М. : Искусство, 1971. 286 с.

7. Самин К.Д. 100 великих архитекторов. М. : Вече, 2001. 385 с.

8. Рахманова А. Баухауз 90 лет спустя // Deutsche Welle. 2009. Режим доступа: $\mathrm{http}: / / \mathrm{dw} . \mathrm{de} / \mathrm{p} / \mathrm{HMNP} /$. Дата обращения: 15.12.2014.

9. Якоби А., Хартман Г., Дендра Г. Баухауз сегодня : лекция в рамках программы OVERVIEWM / Высшая школа архитектуры Дессау / пер. с нем. О.Т. Ивановой. 2008. Режим доступа: http://archi.ru/events/1490/vysshaya-shkola-arhitektury-dessau-diabauhaus-segodnya-alfred-yakobi-gunnart-hartman-daniel-dendra-germaniya/. Дата обращения: 15.12.2014.

10. Ковешникова Н.А. Дизайн: история и теория. М. : Омега-Л, 2009. 224 с.

11. Meyer H. Bauen und Gesellschaft. Schriften, Briefe, Projekte. Dresden: VEB Verlag der Kunst Dresden, 1980. $412 \mathrm{~s}$.

12. Семина А. Обратим ремесло на благо искусства // Дайджест недвижимости. 2014. № 8 (95). С. 59-64.

13. Кузнецов О.Л., Большаков Б.Е. Устойчивое развитие: универсальный принцип синтеза естественных, технических и социальных знаний // Устойчивое развитие: наука и практика. 2009. № 1 (2). С. 1-12.

14. Яськова Н.Ю. Механизмы инвестирования в устойчивое развитие // Экономика строительства. 2010. № 2. С. $40-45$

15. Яськова Н.Ю., Матвеева М.В. Инновационный фокус инвестиционной деятельности в рамках модернизации национальной экономики // Економічний часописXXI. 2014. T. 1. № 1-2. C. $42-45$. 
Поступила в редакцию в декабре 2014 г.

О б а в торе : Яськова Наталья Юрьевна - доктор экономических наук, профессор, профессор кафедры экономики и управления в строительстве, Московский государственный строительный университет (ФГБОУ ВПО «МГСУ»), 129337, г. Москва, Ярославское шоссе, д. 26, 8 (495) 287-49-19, mcua3@yandex.ru.

Дл я ц и т и ров ан и я : Яськова Н.Ю. Циклическое «дежавю» парадигм развития сферы недвижимости // Вестник МГСУ. 2015. № 1. С. 112-119.

\section{N.Yu. Yas'kova}

\section{CYCLIC “DEJA VU” OF REAL ESTATE INDUSTRY DEVELOPMENT PARADIGMS}

The practical projections of cyclic theories are of a great interest. Our preferences moved again from apartment houses and vertical cities to low-rise buildings. Circles set the development vector for natural, human sciences and sciences on society.

The article researches the problem of cyclic development of scientific schools and their innovation ideas in the sphere of space-territory property development. The phases of the cycle were researched on the example of Bauhaus architecture school. This enables to reveal the demands and specifics of the development of new technological platforms, as well as to create the effective formats of public-private partnership. Cyclicity of business activity development under the conditions of awareness of the evolution of senses of interdisciplinary approaches utilization permits to produce the adequate development paradigm.

Key words: architectural school, craft, innovation platform, space restructuring, state development, development strategy, urban environment, sustainable development, economic-organizing reliability, planning.

\section{References}

1. Yas'kova N.Yu., Sergeev I.M., Polinov A.A. Nezavershennoe stroitel'stvo i virtual'nyy ekonomicheskiy rost [Construction in Progress and Virtual Economic Growth]. Ekonomika stroitel'stva [Construction Economy]. 2004, no. 8, pp. 2-13. (In Russian)

2. Yas'kova N.Yu. Tendentsii razvitiya stroitel'nykh korporatsiy v novykh usloviyakh [Development Trends of Construction Corporations in New Environment]. Nauchnoe obozrenie [Scientific Review]. 2013, no. 6, pp. 174-178. (In Russian)

3. Yas'kova N.Yu. Razvitie kontseptual'nykh polozheniy upravleniya protsessami investitsionno-stroitel'noy deyatel'nosti [Development of Conceptual Provisions of Process Management in Investment and Construction Activities]. Vestnik IrGTU [Bulletin of Irkutsk State Technical University]. 2012, no. 11(70), pp. 278-280. (In Russian)

4. Droste M. Baukhauz (1919-1933). Reforma $i$ avangard [Bauhaus Bauhaus 19191933. Reform and Avant-garde]. Translated from French by Yu. Yu. Kotova. Moscow, Art-Rodnik Publ., 2008, 96 p. (In Russian)

5. Kharshak M. «Baukhaus» - mesto, gde rodilsya dizayn [Bauhaus - a Place Where Design Was Born]. Advertology.Ru. Available at: http://www.advertology.ru/article13833.html. Date of access: 15.12.2014. (In Russian)

6. Gropius W. Granitsy arkhitektury [Boundaries of Architecture]. Translated from English by A.S. Pinsker, V.R. Aronov, V.G. Kalish. Moscow, Iskusstvo Publ., 1971, 286 p. (In Russian)

7. Samin K.D. 100 velikikh arkhitektorov [100 Grear Architects]. Moscow, Veche Publ., 2001, 385 p. (In Russian)

8. Rakhmanova A. Baukhauz 90 let spustya [Bauhaus 90 Years Later]. Deutsche Welle. 2009. Available at: http://dw.de/p/HMNP/. Date of access: 15.12.2014. (In Russian)

9. Yakobi A., Khartman G., Dendra G. Baukhauz segodnya : lektsiya v ramkakh programmy OVERVIEWM [Bauhaus Today : a Lecture in Frames of the Program OVERVIEWM]. Vysshaya shkola arkhitektury Dessau [Higher School of Architecture DIA]. Transkated from 
German by O.T. Ivanova. 2008. Available at: http://archi.ru/events/1490/vysshaya-shkolaarhitektury-dessau-dia-bauhaus-segodnya-alfred-yakobi-gunnart-hartman-daniel-dendragermaniya/. Date of access: 15.12.2014. (In Russian)

10. Koveshnikova N.A. Dizayn: istoriya i teoriya [Design: History and Theory]. Moscow, Omega-L Publ., 2009, 224 p. (In Russian)

11. Meyer H. Bauen und Gesellschaft. Schriften, Briefe, Projekte. Dresden, VEB Verlag der Kunst Dresden, 1980, $412 \mathrm{~s}$.

12. Semina A. Obratim remeslo na blago iskusstva [Let Us Turn Craft for the Benefit of Art]. Daydzhest nedvizhimosti [Real Estate Digest]. 2014, no. 8 (95), pp. 59—64. (In Russian)

13. Kuznetsov O.L., Bol'shakov B.E. Ustoychivoe razvitie: universal'nyy printsip sinteza estestvennykh, tekhnicheskikh i sotsial'nykh znaniy [Sustainable Development: The Universal Principle of the Synthesis of Natural, Technical and Social Knowledge]. Ustoychivoe razvitie: nauka i praktika [Sustainable Development: Science and Practice]. 2009, no. 1 (2), pp. 1-12. (In Russian)

14. Yas'kova N.Yu. Mekhanizmy investirovaniya v ustoychivoe razvitie [Mechanisms of Investing in Sustainable Development]. Ekonomika stroitel'stva [Construction Economy]. 2010, no. 2, pp. 40-45 (In Russian)

15. Yas'kova N.Yu., Matveeva M.V. Innovatsionnyy fokus investitsionnoy deyatel'nosti v ramkakh modernizatsii natsional'noy ekonomiki [Innovative Focus of Investment Activity in the Framework of National Economy Modernization]. Ekonomichniy chasopis-XXI [Economy Journal-21]. 2014, vol. 1, no. 1-2, pp. 42—45. (In Russian)

About the author: Yas'kova Natal'ya Yur'evna - Doctor of Economic Sciences, Professor, Department of Economy and Management in Construction Water Supply, Moscow State University of Civil Engineering (MGSU), 26 Yaroslavskoe shosse, Moscow, 129337, Russian Federation; +7 (495) 287-49-19, mcua3@yandex.ru.

For citation: Yas'kova N.Yu. Tsiklicheskoe "dezhavyu» paradigm razvitiya sfery nedvizhimosti [Cyclic "Deja Vu" of Real Estate Industry Development Paradigms]. Vestnik MGSU [Proceedings of Moscow State University of Civil Engineering]. 2015, no. 1, pp. 112-119. (In Russian) 